\title{
Summary of: Predicting the choice of anaesthesia for third molar surgery - guideline or the easy-line?
}

\begin{tabular}{|c|}
\hline FULL PAPER DETAILS \\
\hline $\begin{array}{l}\text { 1Edinburgh Dental Institute, Lauriston Building, } \\
\text { Lauriston Place, Edinburgh, EH3 9HA } \\
\text { *Correspondence to: Miss Stephanie Sammut } \\
\text { Email: stefsammut@gmail.com }\end{array}$ \\
\hline $\begin{array}{l}\text { Refereed Paper } \\
\text { Accepted 10 October } 2012 \\
\text { DOI: } 10.1038 / \text { sj.bdj.2013.163 } \\
\text { 'British Dental Journal 2013; 214: E9 }\end{array}$ \\
\hline
\end{tabular}

\author{
S. Sammut, ${ }^{* 1}$ V. Lopes, ${ }^{1}$ A. Morrison ${ }^{1}$ and N. J. Malden ${ }^{1}$
}

Objective To observe trends in choice of anaesthetic for mandibular third molar surgery in the Combined Department of Oral and Maxillofacial Surgery and Oral Medicine, based at the Edinburgh Dental Institute (EDI) and St John's Hospital $(\mathrm{SJH})$ in Livingston. Method Data were collected retrospectively from electronic patient records for 301 consecutive new referrals for mandibular third molar surgery from general dental practitioners to each of the oral and maxillofacial departments in the EDI and SJH from the 1 September 2009 onwards. Date of consultation, grade of assessing clinician, age, gender, postcode, required surgical procedure, choice of anaesthetic and predicted difficulty of procedure were analysed. Results One hundred and fifty patients were seen at the EDI and 151 at SJH. There was no statistically significant difference in the proportion of male and female patients or age of patients presenting at each site. Seventeen patients (11.3\%) were listed for a general anaesthetic, 21 (14\%) for conscious intravenous sedation and 112 (74.7\%) for local anaesthetic at EDI. At SJH 57 patients (37.7\%) were listed for a general anaesthetic, 30 (19.9\%) for conscious intravenous sedation and 64 (42.4\%) for local anaesthetic. There was only a small difference in the difficulty of cases at the two sites, though there was a significant difference in socioeconomic deprivation between the two populations. Conclusions Significantly more general anaesthetics are being prescribed for mandibular third molar surgery at SJH than the EDI. This finding is not related to difficulty of the cases presenting at each site but may be related to the nature of a maxillofacial clinic compared to a dedicated oral surgery centre. The difference in socioeconomic deprivation may have had an impact on patient decisions.

\section{EDITOR'S SUMMARY}

A lay person may be mystified as to when caries is or isn't caries, that is to say when a cavity is or isn't a cavity. To us it is a much clearer definition (or is it is?) based on the degree of demineralisation, the patient's caries prone risk and a variety of other factors including availability of materials and, whether we care to acknowledge it or not, the system of remuneration.

Using a similar train of thought perhaps the results of this research are not surprising, even though they are illuminating. The treatment plan of removal of one or more third molars is arrived at through a diagnostic filter influenced by the patient to the extent that they may well have presented complaining of pain, such as due to pericoronitis. The execution of that treatment plan can then follow a relatively complex series of deci- sions so that 'surely taking a tooth out is taking a tooth out' becomes as mysterious as when is a hole not a hole?

At least two individuals are concerned together with their priorities and preferences; the patient and the surgeon. Mapped onto these considerations are the availability of anaesthetic and analgesic options, time, convenience and of course money. The impact of the care delivery system on the decision-making process is central to the area of debate into which these research findings enter. To those of us with experience of decision making by individuals it comes as no surprise that a particular department in a particular hospital will do it 'their way'. Similarly, that patients from defined demographic groups will prefer to have it done 'their way'.

Third party payers around the globe attempt without pause to regulate the way in which the money they dispense is allocated according to rules, regulations and guidance. Until the individual is removed from the equation funding bodies are doomed to failure.

The full paper can be accessed from the $B D J$ website (www.bdj.co.uk), under 'Research' in the table of contents for Volume 214 issue 4.

Stephen Hancocks Editor-in-Chief

DOI: 10.1038/sj.bdj.2013.191 


\section{TO ACCESS THE BDJ WEBSITE TO READ THE FULL PAPER:}

- BDA Members should go to www.bda.org.

- Click the 'login' button on the right-hand side and enter your BDA login details.

- Once you have logged in click the 'BDJ' tab to transfer to the BDJ website with full access.

IF YOUR LOGIN DETAILS DO NOT WORK:

- Get a password reminder: go to www.bda.org, click the login button on the right-hand side and then click the forgotten password link.

- Use a recommended browser: we recommend Microsoft Internet Explorer or Mozilla Firefox.

- Ensure that the security settings on your browser are set to recommended levels.

IF YOU HAVE NOT YET SIGNED UP TO USE THE BDA WEBSITE:

- Go to www.bda.org/getstarted for information on how to start using the BDA website.
IN BRIEF

- Shows that a maxillofacial environment is more likely to lead to the prescription of general anaesthetic for third molar removal than a pure oral surgery clinic.

- Promotes risk reduction by discouraging the use of general anaesthesia for third molar surgery.

- Recognises that choice of anaesthesia is dependent on multiple factors.

- Highlights IV sedation as a useful and safe modality for anxiety management.

\section{COMMENTARY}

The delivery of quality care at a reduced cost is a central tenet of the Department of Health's Quality, Innovation, Productivity, Prevention (QIPP) programme, with the 'goal to improve the quality of care the NHS delivers while making up to $£ 20$ billion of efficiency savings by 2014-15.' Where, by whom and how oral surgery services should be delivered most effectively has been the subject of much debate for many years.

With changes in commissioning south of the border, increasing patient choice and striving to treat patients closer to home; the delivery of oral surgery care is changing.

For example, the oral surgery review included a brief economic evaluation of possible savings by moving services into primary care, quoting possible cost reductions of around 50\% with oral surgical specialists and 80\% with dentists with a specialist interest. ${ }^{2}$

However, an earlier review of other surgical specialties highlighted some possible concerns with shifting services from secondary to primary care. While an increase in local access was seen, the corresponding hospital workload did not decrease - there was an increased cost to the health service as a result of overall expansion, implementation issues for training/equipment and often worse, patient outcomes. ${ }^{3}$

This paper by Sammut et al. demonstrates marked differences in choice of anaesthesia for third molar surgery within different secondary care settings, which are not explained by surgical or patient factors. Rather, it appears that the findings provide empirical evidence for patients looking more like nails when surgeons are more experienced with the use of a hammer.

These findings obviously have cost implications, suggesting that significant efficiency savings could be made by providing more oral surgery services in secondary care under local anaesthesia with or without sedation. However, this does not indicate a need for a move into primary care.

In addition to cost, quality of care and patient centred outcomes are central issues in this debate. Unfortunately, data on patient outcomes in relation to choice of anaesthesia and delivery of oral surgery in different settings are scarce, and the lack of such data is one limitation of this study. The pending changes to oral surgery provision in England should provide an ideal research platform and allow the generation of data to facilitate evidencebased decision making in this area.

\section{David Pearson and Thomas Dietrich University of Birmingham}

1. Department of Health. QIPP. Online information available at http://www.dh.gov.uk/health/category/policy-areas/nhs/quality/qipp/ (accessed February 2013)

2. Medical Education England. Review of oral surgery services and training. England: MEE. Online article available at http://www.mee.nhs.uk/PDF/ os review.pdf (accessed February 2013).

3. Sibbald B, McDonald R, Roland M. Shifting care from hospitals to the community: a review of the evidence on quality and efficiency. J Health Serv Res Policy 2007; 12: 110-117.

\section{AUTHOR QUESTIONS AND ANSWERS}

1. Why did you undertake this research? This research was undertaken to highlight a perceived difference in the way general anaesthesia was prescribed for third molar surgery in two contrasting clinical environments with access to different clinical resources. We subsequently showed this was the case. We also felt that intravenous sedation was underutilised. We wished to show that intravenous sedation is a safe and effective modality for anxiety management in third molar surgery and to promote its use.

2. What would you like to do next in this area to follow on from this work?

Following informative and educational sessions with the workforce in both sites, we plan to repeat the investigation to see whether there is any change in practice following intervention. We are also running a patient experience questionnaire for individuals treated under all three modalities (local anaesthetic, intravenous sedation and general anaesthetic) in an attempt to highlight patient preferences. 